\title{
Pulmonary complications after long term amiodarone treatment
}

\author{
J Roca, M Heras, R Rodriguez-Roisin, J Magriñà, A Xaubet, G Sanz
}

\begin{abstract}
Background Amiodarone hydrochloride is an antiarrhythmic agent useful in arrhythmias refractory to standard therapy. Although interstitial pneumonitis is known to be its most serious side effect, several aspects of amiodarone lung toxicity are still controversial.

Methods Pulmonary side effects were examined in a sample of 61 symptomless patients (mean (SD) age $55(7)$ years) who had had long term treatment with amiodarone (daily maintenance dose $\mathbf{4 0 0}$ mg), selected from $\mathbf{4 8 2}$ men attending the University of Barcelona myocardial infarction project. To allow for the confounding effects of coronary artery disease and tobacco history on lung function, 46 patients who had taken amiodarone for more than one year were matched with a control group from the same population. Subjects underwent measurement of lung volumes, arterial blood gas analysis and an incremental bicycle exercise test.
\end{abstract}

Results Most lung function values were close to predicted values, though there was a small increase in resting alveolar-arterial oxygen tension difference $\left(\mathrm{A}-\mathrm{aDO}_{2}\right)$ at rest $(4.8(1 \cdot 4) \mathrm{kPa}$ in both groups). There were no differences in the results of forced spirometry or static lung volumes between the two groups, or in the fall in $\mathrm{A}-\mathrm{aDO}_{2}$ from rest to exercise. There was a small difference between the amiodarone and the control group in transfer factor for carbon monoxide corrected for lung volume (KCo 1.67 (0.3) and $1.83(0.3) \mathrm{mmol} \mathrm{min}^{-1} \mathrm{kPa}^{-1} 1^{-1}$ respectively) and in exercise capacity (140 (25) and $120(30) w$ ). Only three patients showed lung function impairment consistent with pneumonitis. No relation between lung function measures and cumulative doses of amiodarone or desethylamiodarone was found.

Conclusions The prevalence of clinically evident pulmonary side effects was $4.9 \%$, which is lower than that reported in studies in which higher daily maintenance doses of amiodarone were given. The slightly lower KCO values and lower work load achieved by the patients taking amiodarone suggest a small effect of amiodarone in doses of $400 \mathrm{mg}$ on lung function. A role for individual susceptibility to pulmonary complications of amiodarone treatment is suggested.
Amiodarone hydrochloride is a benzofurane derivative that was used widely as a coronary vasodilator in Europe from 1967 to the late 1970 s. $^{1}$ It started to be used as an experimental antiarrhythmic agent in the United States in the early $1980 \mathrm{~s},{ }^{2}$ and is effective in $75-80 \%$ of cases of supraventricular and ventricular arrhythmia refractory to standard antiarrhythmic agents. ${ }^{3-5}$ The effectiveness of amiodarone is, however, offset by various side effects that limit its long term therapeutic use. Most prominent among these are cutaneous and neurological manifestations, thyroid dysfunction, hepatotoxicity, muscle weakness, ocular disturbances, and pulmonary complications. ${ }^{5}$ Interstitial pneumonitis associated with amiodarone was first reported by Rotmensch in $1980^{6}$ and is often its most serious side effect. ${ }^{5-11}$ Several aspects of amiodarone lung toxicity are still controversial-namely, its prevalence (which has ranged from 1 to $20 \%^{510-12}$ ) and the precise pathophysiological mechanism, which remains poorly understood. ${ }^{13-15}$ Routine monitoring of pulmonary function, particularly single breath transfer factor for carbon monoxide (TLCO), has been recommended for early detection of pulmonary complications by Kudenchuk and associates. ${ }^{10}$ Their results have not, however, been reproduced in other series. ${ }^{81112}$

The present cross sectional study was specifically aimed to assess pulmonary side effects of amiodarone in patients with coronary disease having long term treatment with the drug. Special care was taken in selecting the sample population and in the protocol design to ensure compliance with treatment and to avoid any confounding effect of subclinical cardiac failure or smoking habit on pulmonary function.

\section{Methods}

\section{POPULATION STUDIED}

The original sample consisted of 61 subjects who had received amiodarone for a cardiac arrhythmia; 46 of them had been treated with amiodarone for at least one year and these were matched with a control group of 46 subjects. Both groups of subjects were selected from the University of Barcelona myocardial infarction project, reported in full elsewhere. ${ }^{17}$ Briefly, patients with a definite myocardial infarction were admitted to the coronary care unit of our hospital, where they were monitored for at least five days. Patients underwent right and left heart catheterisation and selective coronangiography four weeks later, the percutaneous 
femoral approach being used. They had an exercise test six months after the infarct and each year thereafter. All patients were seen regularly by the same physician every three to six months in the outpatient clinic. Their clinical and angiographic records have been reported. ${ }^{17}$

Patients treated with amiodarone received an initial loading dose of $600 \mathrm{mg}$ per day during the first week, followed by a daily maintenance dose of $400 \mathrm{mg}$ for five days a week. The mean (SD) cumulative dose was 325 (160)g (range $27-648 \mathrm{~g}$ ) and mean duration of treatment $35 \cdot 1$ (16.8) months (range 2-76 months). Plasma was taken for measurement of concentrations of amiodarone and desethylamiodarone but because of technical problems these were determined in only 26 patients. The mean plasma concentration of amiodarone was 1.23 (1.02) $\mu \mathrm{g} / \mathrm{ml}$ (range $0.13-3.4 \mu \mathrm{g} / \mathrm{ml}$ ) and of desethylamiodarone $1.19(0.82) \mu \mathrm{g} / \mathrm{ml}$ (range $0 \cdot 1-2.68 \mu \mathrm{g} / \mathrm{ml}$ ). In the remaining 35 individuals we relied on clinical methods to confirm that patients took amiodarone, including electrocardiography and examination for corneal microdeposits with a split lamp. All patients had either a plasma amiodarone determination or a corneal examination to ensure compliance with amiodarone treatment.

Control group A control group was included to address the confounding effect of coronary disease on the results of the pulmonary function tests. The 46 patients who had received amiodarone for more than one year were paired individually with 46 non-treated individuals from the same project. ${ }^{17}$ Both groups were matched according to age (five year interval), presence or absence of smoking (they were classified as smokers, lifetime non-smokers, and ex-smokers), chronic cough or phlegm (yes or no), left ventricular ejection fraction risk groups (up to $20 \%, 21-49 \%$, and $50 \%$ or more), and left ventricular end diastolic pressure $\left(5.0 \mathrm{~mm} \mathrm{Hg}\right.$ interval). ${ }^{17}$ Patients with reinfarction were excluded.

\section{PROTOCOL}

Patients were given an extended questionnaire based on the epidemiology standardisation project of the American Thoracic Society. ${ }^{18}$ Specific questions were appended to identify non-pulmonary complications related to the long term use of amiodarone, including cutaneous manifestations; muscular weakness; and neurological, ocular, gastrointestinal, and thyroid disturbances. A physical examination and chest radiography were performed in each case. Chest radiographs were reviewed and compared with the ILO/UICC standard radiographs used for assessment of pneumoconioses. ${ }^{19}$ Hepatic and thyroid function were measured. ${ }^{20}$ Patients were matched according to how long after the myocardial infarction the lung function measurements were made; for the amiodarone group the mean was $4 \cdot 7$ (SD $1.9)$ years and for the control group 5.9 (1.7) years $(p<0.003)$.

Routine pulmonary function tests were per- formed at the time of the study as follows: (1) intrathoracic gas volume (Vtg) and specific airways conductance (sGaw) were measured with a constant volume plethysmograph (Body Pneumo-test; E Jaeger, Würzburg, Germany); (2) single breath transfer factor for carbon monoxide (TLCO) (PK Morgan, model A, Chatham, UK); (3) arterial blood gas tensions at rest (BMS3 MK2, Radiometer, Copenhagen, Denmark) in 41 of 46 patients in each group; and (4) slow and forced spirometry before and after a bronchodilator (salbutamol) (HP 47804A Pulmonary System, Waltham, Montana, Massachusetts). An incremental cycling exercise was performed by 40 of the 46 patients in each group. Six patients treated with amiodarone and their controls were excluded from the exercise study because of lack of cooperation (four cases) or technical problems (two cases). The exercise protocol consisted of a workload increase of 20 watts every minute to the maximal tolerated work load. Arterial blood gas tensions at rest and during maximal exercise were obtained through an indwelling radial or brachial artery catheter (Seldicath, Plastimed, Saint-Leu-LaForêt, France) placed in the non-dominant wrist or arm.

A diagnosis of pneumonitis was established according to three or more of the following criteria: bilateral end expiratory crepitations; chest radiograph with infiltrates in the lung parenchyma; ${ }^{19}$ restrictive ventilatory pattern (FVC $<\mathbf{8 0} \%$ predicted, $\mathrm{FEV}_{1} / \mathrm{FVC}$ ratio $\geqslant$ $80 \%$, TLC $<80 \%)^{21}$; TLCO $<80 \%$ predicted ${ }^{22}$; arterial oxygen tension $\left(\mathrm{PaO}_{2}\right)$ at rest < $10.7 \mathrm{kPa}$; and/or an increase in the alveolararterial oxygen tension difference $\left(\mathrm{A}-\mathrm{aDO}_{2}\right)$ of more than $0.6 \mathrm{kPa}$ during the exercise test in the absence of functional limitations suggesting cardiac failure. ${ }^{23}$ In all the patients suspected of having pneumonitis pulmonary infiltrates with no evidence of left ventricular failure were reported by an independent radiologist unaware of the patient's treatment. The diagnosis was supplemented by a positive gallium67 lung scan and an abnormal count of inflammatory cells in bronchoalveolar lavage fluid. ${ }^{24}$ Pulmonary haemodynamics were measured with a Swan-Ganz catheter in one of the three patients (No 3) with suspicion of pneumonitis only.

\section{DATA ANALYSIS}

Results are presented as mean (SD) values. Paired Student's $t$ tests and one way analysis of covariance, with age as the covariate, were used to assess differences between amiodarone treated and control groups ( $n=46$ each). Relations between lung function and cumulative dose of amiodarone were examined by using a stepwise multiple regression analysis. In the regression formula each lung function index was the dependent variable; the cumulative dose of amiodarone, age, height, and body weight were covariates. A p value below $\mathbf{0 . 0 5}$ was considered statistically significant. 
Table 1 Lung function results in the three patients with presumed pulmonary side effects of amiodarone

\begin{tabular}{lclc}
\hline Patient No: & 1 & 2 & 3 \\
\hline FVC (\% pred) & 101 & 82 & $68\left(^{\star}\right)$ \\
FEV $_{1}$ (\% pred) & 99 & 89 & $61\left(^{\star}\right)$ \\
FEV $/$ FVC ratio & 72 & 82 & 70 \\
TLC (\% pred) & 94 & $66\left(^{\star}\right)$ & 90 \\
RV (\% pred) & 87 & $42\left(^{\star}\right)$ & 107 \\
RV/TLC ratio & 36 & 29 & 42 \\
TLCo (\% pred) & 88 & $59\left(^{\star}\right)$ & $47\left(^{\star}\right)$ \\
PaO $_{2}(\mathrm{kPa})$ & $7 \cdot 9\left(^{\star}\right)$ & $9.0\left(^{\star}\right)$ & $7 \cdot 3\left(^{\star}\right)$ \\
$\mathrm{PaCO}_{2}(\mathrm{kPa})$ & 4.9 & $5 \cdot 1$ & $4 \cdot 8$ \\
\hline
\end{tabular}

^Results below the lower reference limit.

FVC-forced vital capacity; FEV - forced expiratory volume in one second; FEV / FVC-ratio of actual values of $\mathrm{FEV}_{1}$ and FVC; TLC-total lung capacity; RVresidual volume; RV/TLC ratio expressed as actual value TLCO-single-breath $\mathrm{CO}$ transfer capacity; $\mathrm{PaO}_{2}$-arteria partial pressure of oxygen; $\mathrm{PaCO}_{2}$-arterial partial pressure of carbon dioxide.

\section{Results}

PREVALENCE OF AMIODARONE INTERSTITIAL PNEUMONITIS

Of the initial 61 patients receiving amiodarone, 53 were ex-smokers, three lifetime non-smokers, and five current smokers. Seven patients had had mild cardiac failure and were receiving digoxin and diuretics; the remaining 54 were symptomless, in functional class $\mathrm{I} .{ }^{23}$ None of the patients had clinical or radiographic features of cardiac failure at the time of the study. No differences in pulmonary function were found between the 46 patients who had received amiodarone for more than one year and the 15 who had been treated for a shorter time. None of the 61 patients had severe nonpulmonary side effects from amiodarone. Mild to moderate cutaneous manifestations, mainly photosensitivity or increased cutaneous pigmentation or both, were present in 28 patients;

Table 2 Comparison of anthropometric data, matching indices, and lung function results for amiodarone $(n=46)$ and control $(n=46)$ groups ${ }^{\star}$

\begin{tabular}{|c|c|c|c|}
\hline & Amiodarone & Control & $p$ \\
\hline Age (y) & $54 \cdot 3(7 \cdot 8)$ & $56.6(6.5)$ & $<0.05$ \\
\hline Height $(\mathrm{cm})$ & $166(7 \cdot 1)$ & $166(6 \cdot 5)$ & - \\
\hline Weight (kg) & $72 \cdot 0(9 \cdot 5)$ & $72 \cdot 8(8 \cdot 3)$ & - \\
\hline Tobacco (pack years) & $30 \cdot 3(21 \cdot 0)$ & $28 \cdot 1(16 \cdot 0)$ & - \\
\hline Ejection fraction (\%) & $47 \cdot 1(13 \cdot 2)$ & $48 \cdot 1(13.6)$ & - \\
\hline $\operatorname{EDVP}(\mathrm{mm} \mathrm{Hg})$ & $12.0(5.5)$ & $13.4(5.9)$ & - \\
\hline $\mathrm{PAP}(\mathrm{mm} \mathrm{Hg})$ & $13 \cdot 8(3 \cdot 3)$ & $13.9(3 \cdot 7)$ & - \\
\hline Years after amiodarone & $4 \cdot 7(1.9)$ & $5.9(1.7)$ & $<0.003$ \\
\hline $\mathrm{FVC}(\mathrm{ml})$ & $4060(619)$ & $3951(721)$ & - \\
\hline $\mathrm{FEV}_{1}(\mathrm{ml})$ & $2907(561)$ & $2826(609)$ & - \\
\hline FEV $/$ FVC ratio & $71(7)$ & $71(7)$ & - \\
\hline $\mathrm{FEF}_{25-75}(1 / \mathrm{min})$ & $2.25(1.05)$ & $2.29(0.89)$ & - \\
\hline TLC $(\mathrm{ml})$ & $6569(775)$ & $6403(1030)$ & - \\
\hline $\mathrm{RV}(\mathrm{ml})$ & $2907(561)$ & $2826(609)$ & - \\
\hline RV/TLC ratio & $34(7)$ & $35(6)$ & - \\
\hline sGaw (SI unit) & $1.63(0.6)$ & $1.59(0.6)$ & - \\
\hline TLCO (SI unit) & $9.03(1.8)$ & $9.60(1 \cdot 7)$ & - \\
\hline Kco (SI unit) & $1.67(0.3)$ & $1.83(0.3)$ & $<0.04$ \\
\hline $\mathrm{PaO}_{2}(\mathrm{kPa})$ & $9 \cdot 3(1 \cdot 5)$ & $9.5(1.0)$ & - \\
\hline $\mathrm{PaCO}_{2}(\mathrm{kPa})$ & $4 \cdot 8(0 \cdot 6)$ & $4.8(0.4)$ & - \\
\hline $\mathrm{A}-\mathrm{aDO}_{2}$ at rest $(\mathrm{kPa})$ & $4 \cdot 8(1.4)$ & $4.6(1.0)$ & - \\
\hline $\mathrm{A}-\mathrm{aDo}_{2} \mathrm{E}-\mathrm{r}(\mathrm{kPa})$ & $-1.6(1.3)$ & $-1.5(1.0)$ & - \\
\hline Work load (w) & $120(30 \cdot 2)$ & $140(24.9)$ & $<0.004$ \\
\hline
\end{tabular}

*For arterial blood gas analysis $n=41$; for exercise data $n=40$

EDVP_-end diastolic ventricular pressure; PAP - pulmonary artery pressure; $\mathbf{F E F}_{25-75}$ forced expiratory flow between $25 \%$ and $75 \%$ of FVC; sGaw-specific airways conductance $\left(\mathrm{s}^{-1} \mathrm{kPa}{ }^{\mathrm{I}}\right)$; TLCO (mmol CO $\left.\min { }^{1} \mathrm{kPa}{ }^{-1}\right)$; $\mathrm{KCO}\left(\mathrm{mmol} \mathrm{CO} \min ^{-1} \mathrm{kPa}^{-1} \mathbf{1}^{-1}\right.$, BTPS); $\mathrm{A}-\mathrm{aDO}_{2}$-alveolar-arterial oxygen difference; $\mathrm{E}-\mathrm{R}$-difference between exercise and rest.

For other abbreviations see table 1 . blurred vision in two; a morning sensation of sand in the eye in three; muscle weakness in two; and fine distal tremor in one. There were no gastrointestinal symptoms or clinical signs of thyroid disturbance. Amiodarone treated patients had higher plasma levels of thyroxine and reverse tri-iodothyronine than the control group (thyroxine $8.7(3.3) v 6.2(1.8) \mu \mathrm{g} / 100 \mathrm{ml}$ $\mathrm{p}<0.001$; reverse tri-iodothyronine 388 (155) $v 167(1.8) \mathrm{pg} / \mathrm{ml} ; \mathrm{p}<0.0001)$, findings consistent with enzymatic inhibition of the peripheral conversion of thyroxine to triiodothyronine by amiodarone. ${ }^{16}$

Only three of the 61 patients fulfilled the criteria of possible pneumonitis as defined under "Methods" (table 1). One of the three had a recent history of dyspnoea on mild exercise, dry cough, and muscle weakness, and had a right pleural rub; another had bilateral crackles. The chest radiograph in two patients showed an interstitial infiltrate and the third showed a peripheral alveolar infiltrate. All three patients had arterial hypoxaemia at rest (table 1) and two had a reduction in static lung volumes and TLCo. All improved after amiodarone withdrawal. Two were also treated with oral prednisone (initial dose $1 \mathrm{mg} / \mathrm{kg}$ a day for six weeks followed by a reducing dose for two months in one and six months in the other) until both amiodarone and desethylamiodarone were undetectable. The radiographs, gallium lung scans, and lung function showed progressive improvement at follow up in two patients.

COMPARISON OF LUNG FUNCTION BETWEEN AMIODARONE AND CONTROL GROUPS

There was no difference between the amiodarone and the control groups for height, weight, mean systemic blood pressure, or cardiac functional class ${ }^{23}$ (table 2). Patients in the amiodarone group were slightly younger than the controls. Mean values for maximal expiratory flow rates, static lung volumes, airways conductance, and TLco were close to predicted values in both the amiodarone and the control group. Both groups had mild hypoxaemia at rest and an increased $\mathrm{A}-\mathrm{aDo}_{2}$ (table 2).

There was no difference between the amiodarone and control groups in dynamic and static lung volume, specific airways conductance, TLCO, or helium single breath total lung capacity (VA). The amiodarone group had a slightly lower KCO $(1.67(0.3)$ v $1.83(0.3) \mathrm{mmol}$ $\left.\mathrm{CO} \mathrm{min}^{-1} \mathrm{kPa}^{-1} 1^{-1}\right)(\mathrm{p}<0.04)$. The alveolararterial oxygen difference at maximal work load showed a similar fall from the values obtained at rest in the amiodarone and control groups $(-1.6(1.3)$ and $-1.5(1.0) \mathrm{kPa})$. The maximum tolerated work load was significantly lower in the amiodarone group than in the control group (120 (30) $v 140$ (25) $\mathrm{w}$; p < $0.004)$. The differences between the two groups persisted when the three patients with presumed amiodarone pulmonary fibrosis were removed and the remaining 43 individuals were compared with 43 controls (Kco $1.72(0 \cdot 2) v$

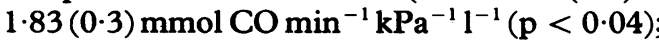
decrease in $\mathrm{A}-\mathrm{aDO}_{2}$ at maximal workload $-1 \cdot 7$ 
(1.3) $v-1.5(1.0) \mathrm{kPa}$; maximum workload 120 (30) $v 138$ (25) w; p $<0.004)$. Finally, there were no significant correlations between any lung function variable and cumulative dose of amiodarone (daily dose times days of treatment) when multiple regression analysis was carried out.

Amiodarone had to be withdrawn in 17 patients $(32 \%)$ originally treated with the drug because it failed as an antiarrhythmic agent. The therapeutic efficacy $(68 \%)$ is slightly lower than that reported from studies ${ }^{3-5810-12}$ with higher daily maintenance doses. Amiodarone was effective in controlling cardiac arrhythmias in the 61 patients in the present study.

\section{Discussion}

This study examined a population of symptomless patients followed by the same cardiologist in the outpatients clinic. ${ }^{17}$ The prevalence of clinically evident pulmonary side effects was $4.9 \%$ (three cases), which is similar to that reported by Rotmensch et al $(3.2 \%)^{25}$ in a multicentre follow up study in which a similar average daily dose of amiodarone had been given. A higher prevalence, ranging from $6 \%$ to $20 \%$, has been reported in studies from the United States, ${ }^{810-12}$ where higher doses of amiodarone are used (loading dose $1400 \mathrm{mg}$ for two to three weeks followed by daily maintenance dose of $600-800 \mathrm{mg}$ ). Our daily maintenance dose of $400 \mathrm{mg}$ provided amiodarone plasma concentrations above the therapeutic threshold $(1 \mu \mathrm{g} / \mathrm{l})$ and, in general, below the toxic threshold of $2.5 \mu \mathrm{g} / 1 .^{25}$

In the present study two of the three patients with presumed pulmonary side effects showed mild to moderate clinical manifestations and the third had a subacute clinical onset. Radiographic and lung function data were in keeping with the diagnosis of pneumonitis in all three patients and the diagnosis was supported by a positive gallium lung scan and an abnormal cell composition of the bronchoalveolar lavage fluid. ${ }^{24}$ The abnormalities tended to resolve after amiodarone was withdrawn.

Pulmonary function tests showed moderate arterial hypoxaemia and an increase in the $\mathrm{A}-\mathrm{aDO}_{2}$. This impairment in respiratory gas exchange at rest cannot be associated with amiodarone, however, because similar abnormalities occurred at rest and during exercise in the control group (table 2). The reduction in the $\mathrm{A}-\mathrm{aDO}_{2}$ during exercise in both groups is consistent with ventilation-perfusion mismatching at rest that improves during exercise. This could be due to underlying coronary disease, despite the fact that the patients did not have functional limitations to suggest heart failure. Alternatively, as many of these patients had smoked heavily, small airway dysfunction could contribute to these mild abnormalities of lung function.

Although the difference was statistically significant, the fact that patients taking amiodarone had a lower Kco than the control group is likely to be of limited clinical significance as it was a small difference. This finding and the lower work load achieved by the patients taking amiodarone might be due to a small but genuine effect of the drug at the doses used in the present study. The similar results for the $\mathrm{A}-\mathrm{aDO}_{2}$ during exercise in the two groups suggests that the lower $\mathrm{Kco}$ in the patients having amiodarone does not explain the difference in maximum work load. The design of the exercise protocol cannot provide a clear explanation for the lower maximum work load observed in the amiodarone group (table 2). It could be due to a direct cardiac effect of amiodarone. Both groups were studied about five years after the acute coronary episode, so the slightly longer time since myocardial infarction in the amiodarone group (table 2) is unlikely to account for the difference.

In summary, our patients receiving amiodarone for a year showed a low prevalence of lung function disturbances that is likely to be due to amiodarone. Lung function impairment compatible with amiodarone pneumonitis was observed in only three patients. Despite differences in study design, our results are consistent with a carefully conducted study done by Magro et al. ${ }^{12}$ They showed that routine pulmonary function tests failed to predict amiodarone pulmonary side effects in asymptomatic patients, but were useful in patients with mild manifestations of the disease. They reported that a fall in TLCo of $15 \%$ or more in a patient with clinical suspicion of pulmonary toxicity gives a $100 \%$ sensitivity and an $89 \%$ specificity for the diagnosis of pulmonary complications of amiodarone treatment. Such figures could not be extrapolated to symptomless patients. ${ }^{12}$

A direct cytotoxic effect of amiodarone on the lung has been strongly supported by studies in animal models, ${ }^{26}$ clinical studies in patients, ${ }^{12}$ and epidemiological findings. ${ }^{5}$ The small differences in pulmonary function (Kco) between the amiodarone and the control group contrast with the large difference in thyroid function indices, ${ }^{20}$ which perhaps suggest a role for individual susceptibility in pulmonary complications of amiodarone treatment.

We thank C Gistau, F Burgos, T Lecha, M Simó, C Argaña, and B Ochoa for their skilful technical assistance and the medical staff who participated in the University of Barcelona myocardial infarction project for their cooperation and care of the patients. The work was supported in part by grants from the Fondo de Investigación Sanitaria (84/864), ACARD (1984), and the Comisión de Investigación de Ciencia y Tecnologia (PA860345).

1 Vastesaeger M, Gillot P, Rasson G. Etude clinique d'une nouvelle médication anti-angoreusse. Acta Cardiol 1967; 22:483-500.

2 Rosenbaum MB, Chiale PA, Halpern MS. Clinical efficacy of amiodarone as an antiarrythmic agent. $\mathrm{Am} \mathrm{J} \mathrm{Cardiol}$ of amiodarone as

3 Heger JJ, Prytowky EN, Jackman WM, et al. Amiodarone: clinical efficacy and electrophysiology during long term therapy for recurrent ventricular tachycardia or ventricular fibrillation. N Engl J Med 1981;305:539-45.

4 Kopelman HA, Horowitz LN. Efficacy and toxicity of amiodarone for the treatment of supraventricular tachyarrhythmias. Progr Cardiovasc Dis 1989;31:355-66.

5 Mason JW. Amiodarone. N Engl J Med 1987;316:455-66.

6 Rotmensch HH, Liron M, Tupilski M, Laniado S. Possible association of Pneumonitis with amiodarone therapy [letter]. Am Heart J 1980;100:412-3.

7 Marchlinski FE, Gansler TS, Waxman HL, Josephson ME Amiodarone pulmonary toxicity. Ann Intern Med 1982; 97:839-45.

8 Rakita L, Sobol SM, Mostow N, Vrobel T. Amiodarone pulmonary toxicity. Am Heart $J$ 1983;106:906-14. 
9 Darmanata JI, van Zandwijk N, Duren DR, et al. Amiodarone pneumonitis: three further cases with a review of published reports. Thorax 1984;39:57-64.

10 Kudenchuk PJ, Pierson DJ, Greene HL, Graham EL, Sears GK, Trobaugh GB. Prospective evaluation of amiodarone toxicity. Chest 1984;86:541-8.

11 Adams GD, Kehoe R, Lesch M, Glassroth J. Amiodaroneinduced pneumonitis: assessment of risk factors and induced pneumonitis: assessment of risk facto

12 Magro SA, Clinton PE, Wheeler SH, Krafchek J, Lin H, Wyndham C. Amiodarone pulmonary toxicity: prospective evaluation of serial pulmonary function tests. $\mathrm{J} \mathrm{Am}$ Coll Cardiol 1988;12:781-8.

13 Akoun GM, Milleron BJ, Gauthier-Rahman S, Mayaud Ch M. Amiodarone-induced hypersensitivity pneumonitis. Evidence of immunological cell-mediated mechanism. Chest 1984;85:133-5.

14 Israel-Biet D, Venet A, Caubarrère I, et al. Bronchoalveolar lavage in amiodarone pneumonitis. Cellular abnormalities and their relevance to pathogenesis. Chest 1987;91: 214-20.

15 Crystal RG, Gadek JE, Ferrans VJ, Fulmer JD, Line BR, Hunninghake GW. Interstitial lung disease: current concepts of pathogenesis, staging and therapy. Am J Med cepts of pathogen

16 Olsen T, Laurberg $P$, Weeke J. Low serum triiodothyronine and high serum reverse triiodothyronine in old age: an effect of disease not age. J Clin Endocrinol Metab 1978; 47:1111-5.

17 Sanz G, Castañer A, Betriu A, et al. Determinants of prognosis in survivors of myocardial infarction. A prospective clinical angiographic study. $N$ Engl $J$ Med
1982;306:1065-70.

18 Ferris GB. Epidemiology standardization project. Am Rev Respir Dis 1978;118 (suppl 2):55-110.

19 International Labour Office and Union Internationale Contre le Cancer. International classification of radiographs of pneumoconiosis. Geneva: International Labour Office, 1980. (Occupational Safety and Health Series, No 22.)

20 Heras M, Roca J, Sanz G, et al. Alteraciones subclinicas producidas por el tratamiento prolongado con amioproducidas por el tratamiento prolon
darona. Rev Esp Cardiol 1987;40:44-50.

21 Roca J, Sanchis J, Agusti-Vidal A, et al. Spirometric reference values from a mediterranean population. Bull reference values from a mediterranean
Eur Physiopathol Respir 1986;22:217-24.

22 Roca J, Rodriguez-Roisin R, Cobo E, Burgos F, Pérez J, Clausen JL. Single-breath carbon monoxide diffusing capacity $\left(\mathrm{TL}_{\infty}\right)$ prediction equations for a mediterranean population. Am Rev Respir Dis 1990;141:1026-32.

23 Goldman L, Mashimoto B, Cook F, Loscalzo A. Comparative reproducibility and validity of systems for assessing cardiovascular functional class. Advantages of a new specific activity scale. Circulation 1981;64:1227-34.

24 Xaubet A, Roca J, Rodriguez-Roisin R, et al. Bronchoalveolar lavage cellular analysis and gallium lung scan in the assessment of patients with amiodarone-induced the assessment of patients with amiodar.

25 Rotmensch $\mathrm{HH}$, Belhassen B, Swanson BN, et al. Steadystate serum amiodarone concentrations: relationships with antiarrhythmic efficacy and toxicity. Ann Intern Med 1984;101:462-9.

26 Martin WJ II, Howard DM. Amiodarone-induced lung toxicity. In vitro evidence for the direct toxicity of the drug. Am J Pathol 1985;120:344-50.

\section{Adventitia}

\section{Bungalow hospital and coral reef}

Saddened by the prospect of rapid dementia following compulsory retirement, I applied without success to a well known charity for work in the third world, possibly in starving East Africa. But within a few days, wheels having clearly worked within wheels, a telephone call came from the Overseas Development Administration, an organisation of which I then knew little. A pleasant interview followed with the senior medical adviser, the redoubtable Dr Penny Key, herself a veteran of several years' single handed practice in the depths of the jungles of Papua New Guinea. I arrived as temporary physician at Honiara, Guadalcanal, capital of the Solomon Islands, within a month.

The geographical surroundings were glorious, in particular the vast high vermilion and indigo cumulus in the evening sky. My quality of life was further enhanced by a heavily populated coral reef in the crystal clear sea, some 20 paces from my quarters.

The work, in a bungalow hospital with basic facilities, was caring for mainly young patients with treatable infective illnesses-sepsis, malaria, and tuberculous infection in roughly equal mix, with a scattering of leprosy. The medical department had been for some months under the sole care of an ethnic Chinese fifth year undergraduate from Melbourne, who was understandably showing signs of stress. Nursing care by locally trained women was excellent and very practical, and highly competent laboratory technicians were very supportive in the absence of a pathologist. Few people live long enough to develop degenerative disease, and ischaemic heart disease was absent, save for the case of Billy Bennett.

This delightful man had a unique record of personal valour in clandestine wartime jungle operations, his particular skills being with the dagger and the hand grenade. He specialised in the immediate burial of the remains down to the last button, so that the regular disap- demoralising to the enemy. His part in the delivery of intelligence to clandestine radio stations in the mountains by native runners, who might cover 30 miles in a night, contributed substantially to military successes in the area. Sadly he was of mixed New Zealand and Melanesian parentage, and thus inherited the genetic makeup which led to his sudden death from cardiac infarction.

Pidgin English was a source of delight, though it was not easy to acquire fluency. I fell in with an Australian naval padre who went round visiting the villages in a helicopter, known locally, and affectionately, as the "bigfellah mixmaster blong God"-one of many fine examples of the genre. Interestingly, the Service handout on tropical diseases, describing malaria, says ". . . the patient becomes hot and dry. He may vomit a lot and become delicious...,", which seems appropriate in a country that in the past was said to incline at times to cannibalism.

Refreshingly, carcinoma of the bronchus was also virtually absent, my only case being the chief of a hill village who presented with advanced and distressing superior vena caval obstruction from an adenocarcinoma in the right upper lobe. On being told that the only treatment available was chemotherapy, likely to have unpleasant side effects and to be of doubtful benefit, he declined and asked with deep courtesy whether he might, without causing offence, return home to seek the help of the village shaman. I visited his village a couple of months later, on the occasion of a pig feast for the opening of a long house for the local church, and was invited to his home, where I was warmly welcomed. Squatting on the earth floor of his grass hut, I was able to observe that the congested superficial veins had disappeared and that the facial oedema was strikingly reduced. His equanimity was complete. I came home with an enhanced sense of humility with regard to Western medicine.-JOHN EDGE 